Published in final edited form as:

Transfusion. 2016 April ; 56(4): 980-993. doi:10.1111/trf.13442.

\title{
Metabolomics in transfusion medicine
}

\author{
Travis Nemkov ${ }^{1}$, Kirk C. Hansen ${ }^{1}$, Larry J. Dumont ${ }^{2}$, and Angelo D'Alessandro ${ }^{1}$ \\ ${ }^{1}$ Department of Biochemistry and Molecular Genetics, University of Colorado Denver-Anschutz \\ Medical Campus, Aurora, Colorado \\ ${ }^{2}$ Department of Pathology, Geisel School of Medicine at Dartmouth, Lebanon, New Hampshire
}

\begin{abstract}
Biochemical investigations on the regulatory mechanisms of red blood cell (RBC) and platelet (PLT) metabolism have fostered a century of advances in the field of transfusion medicine. Owing to these advances, storage of RBCs and PLT concentrates has become a lifesaving practice in clinical and military settings. There, however, remains room for improvement, especially with regard to the introduction of novel storage and/or rejuvenation solutions, alternative cell processing strategies (e.g., pathogen inactivation technologies), and quality testing (e.g., evaluation of novel containers with alternative plasticizers). Recent advancements in mass spectrometrybased metabolomics and systems biology, the bioinformatics integration of omics data, promise to speed up the design and testing of innovative storage strategies developed to improve the quality, safety, and effectiveness of blood products.
\end{abstract}

Here we review the currently available metabolomics technologies and briefly describe the routine workflow for transfusion medicine-relevant studies. The goal is to provide transfusion medicine experts with adequate tools to navigate through the otherwise overwhelming amount of metabolomics data burgeoning in the field during the past few years.

Descriptive metabolomics data have represented the first step omics researchers have taken into the field of transfusion medicine. However, to up the ante, clinical and omics experts will need to merge their expertise to investigate correlative and mechanistic relationships among metabolic variables and transfusion-relevant variables, such as 24-hour in vivo recovery for transfused RBCs. Integration with systems biology models will potentially allow for in silico prediction of metabolic phenotypes, thus streamlining the design and testing of alternative storage strategies and/or solutions.

One century after the pioneering experiments on ex vivo preservation of red blood cells (RBCs), ${ }_{1}^{1}$ transfusion medicine has had countless successes culminating in approximately 108 million units donated per year. ${ }^{2}$ Transfusion of blood products is a mainstay lifesaving intervention for patients requiring massive or chronic transfusion. Results from randomized clinical trials have confirmed the safety and effectiveness of transfusion therapies, ${ }^{3,4}$ while

Address reprint requests to: Angelo D'Alessandro, Department of Biochemistry and Molecular Genetics, University of Colorado Denver Anschutz Medical Campus, Aurora, CO 80045; angelo.dalessandro@ ucdenver.edu.

$\mathrm{TN}, \mathrm{KCH}$, and AD are part of Endura LLC. LJD and AD are consultants for New Health Sciences, Inc. 
restrictive transfusion regimens have been increasingly appreciated to be at least noninferior to liberal strategies. Despite this reassuring evidence, the field of transfusion medicine and the end products that it produces are still evolving. ${ }^{5}$ Indeed, it is now commonly accepted that ex vivo preserved blood cells undergo a wide series of morphologic, structural, and functional alterations, collectively referred to as the "storage lesion." ${ }^{\text {"-8 }}$ The appreciation of this lesion is, in part, due to the burgeoning field of omics technologies and, in particular, metabolomics, as we will review in this article. We will discuss how the introduction of metabolomics in the field of transfusion medicine has the potential to be as relevant as the classic biochemical studies were for the first century of transfusion medicine practices.

\section{STANDING ON THE SHOULDERS OF GIANTS}

As reviewed by Mollison, ${ }^{9}$ Greenwalt, ${ }^{10}$ and Hess, ${ }^{11}$ the history of modern transfusion medicine dates back 100 years. However, the basic discoveries appreciating the importance of calcium and citrate in activation or inhibition of coagulation cascades, respectively, date back at least 40 years earlier. In 1875 , Hammarsten ${ }^{12}$ noted that $\mathrm{CaCl}_{2}$ had a significant effect on the speed of coagulation and the amount of fibrin formed. While Pekelharing and Sabbatini's work provided the rationale for the role of citrate as an anticoagulant through the sequestration of calcium ions, ${ }^{9}$ it was only in 1916 that Rous and Turner ${ }^{1}$ developed the very first storage solution containing an anticoagulant, citrate, and a substrate for energy metabolism, glucose. The solution was designed to hypothermically preserve rabbit RBCs ex vivo for up to 4 weeks for use in a test for syphilis. ${ }^{1}$ Owing to Robertson, ${ }^{13}$ military applications immediately followed in World War I. Although saline adenine and glucose (SAG) were combined by Högman and colleagues in the late 1970s, ${ }^{14}$ mannitol (SAGM) was eventually added in 1981 to formulate the first modern additive solution (AS), allowing for storage of RBCs for up to 6 weeks. ${ }^{15}$ While SAGM is still the most widely used RBC AS in Europe, alternative ASs with similar composition have been designed over the years, such as AS-1, AS-3, AS-5, AS-7, MAP, and PAGGSM. ${ }^{16-21}$ Advancements during the past few decades have been mainly limited to the introduction of plastic bags, the application of leukofiltration strategies, and the appreciation of buffering capacity in mediating adenosine triphosphate (ATP) and 2,3-diphosphoglycerate (DPG) preservation, as extensively reviewed. ${ }^{11,21,22}$

\section{CLASSIC BIOCHEMISTRY AND BLOOD CELL BIOLOGY}

Ideation of ASs to optimize ex vivo preservation of blood cells was primarily driven by a progressively expanded understanding of RBC biology. In this view, classic work from Rapoport and colleagues, ${ }^{23-27}$ Heinrich and colleagues, ${ }^{24,25,28}$ Holmsen, ${ }^{29,30}$ Holzhütter and colleagues, ${ }^{31}$ Lew and Bookchin, ${ }^{32}$ Low and colleagues, ${ }^{33}$ the Giardina group, ${ }^{34}$ and Palsson and colleagues ${ }^{35-37}$ elucidated much of the complexity of RBC and platelet (PLT) metabolic networks. The case of RBCs is particularly striking, in that the absence of nuclei and organelles had prompted investigators to focus on cytosolic reactions, such as glycolysis (Embden-Meyerhof), pentose phosphate pathway, and Rapoport-Luebering shunt. The latter pathway is of key interest since it generates DPG, a metabolite that plays an important role in deoxyhemoglobin stabilization and thus gas transport homeostasis. ${ }^{38}$ In addition to DPG, levels of other high-energy phosphate compounds such as ATP are important markers of 
energy homeostasis in RBCs. Furthermore, these compounds serve as key molecules in transfusion medicine due to their correlation with 24-hour in vivo recoveries. ${ }^{39}$ Thus, the formulation of early and modern ASs was based on a classic biochemical understanding of enzyme kinetics and preferred metabolic substrates, as well as on the appreciation of how these variables are affected by hypothermia and acidification of the intracellular $\mathrm{pH}$, which occurs during routine storage of RBCs and PLTs in the blood bank.

\section{FROM CLASSIC BIOCHEMISTRY TO OMICS TECHNOLOGIES}

Despite a century of successful development and application of transfusion strategies, transfusion medicine experts of the National Heart, Lung, and Blood Institute in 2015 have agreed upon an ambitious agenda focused on the optimization of collection, processing, and storage strategies, with the goal of providing the best quality and safest care to the recipients. ${ }^{5}$ Novel analytical tools, such as the omics technologies, have been described as key technologies to fulfill this agenda. ${ }^{5}$

The term "omics" refers to all of the analytical approaches that generate big data on single classes of biomolecules, such as proteomics for proteins and metabolomics for smallmolecule metabolites ( $<1.5-\mathrm{kDa}$ molecular weight compounds). Application of omics technologies such as proteomics has shed light on the real complexity of the RBC enzymatic machinery, revealing the presence of approximately 2000 distinct entries. ${ }^{40,41}$ Analogously, almost 4000 PLT proteins have been confidently identified through proteomics. ${ }^{42}$ Metabolomics has further elaborated on insights gained through proteomics by providing perspectives into enzymatic function as supported by the production and usage of small molecule metabolites. ${ }^{43}$ On the basis of this updated information, metabolic maps of RBCs and PLTs have been redrawn, paving the way for state-of-the-art systems biology analyses that integrate metabolomics data through computational analysis. ${ }^{43,44}$

Omics applications relevant to the field of transfusion medicine have been recently reviewed. 6,8,22 However, confusion among transfusion medicine experts may arise about the advantages and disadvantages of the different available analytical approaches, the interpretation of the results, and the usefulness of descriptive analyses in the absence of correlative or mechanistic association with transfusion-relevant variables such as hemolysis or 24-hour in vivo survival. ${ }^{45}$ In the next paragraphs we will provide an overview of currently available metabolomics technologies, as well as the accompanying advantages and disadvantages. We will further provide a general description of how metabolomics has impacted the field to date and how we envisage its contribution to advances in transfusion medicine in the upcoming years.

\section{THE METABOLOMICS WORKFLOW: INFORMATION RELEVANT TO TRANSFUSION EXPERTS}

Although metabolomics strategies enable a comprehensive analysis of a given class of biomolecules, there is no single approach that covers the whole "metabolome." While different considerations apply depending on the type analysis, an overview of the basic workflow is provided in Fig. 1A. 


\section{Step 1: extraction}

Sample preparation is usually optimized to extract and analyze the hydrophilic and lipophilic small-molecule fraction separately by extracting and resuspending each fraction in a solution containing low or high organic percentages, respectively. While all classic extraction methods—extensively reviewed by Mushtaq and coworkers ${ }^{46}$ —require a step for protein precipitation (usually with ice-cold methanol), variants of these methods include vigorous mixing and centrifugation upon resuspension in different ratios of distilled water and organic solvents, including methanol, acetonitrile, and chloroform -in order of organic solvent strength. Solvent ratios vary based on the class of compounds of interest and depend on higher percentages of stronger organic solvents for more hydrophobic analytes (e.g., triglycerides, cholesterols). To cope with technical variability, internal standards such as xenometabolites or stable isotope labeled compounds can be spiked into the lysis and extraction buffer. ${ }^{47,48}$ Since metabolic enzyme activities are strictly temperature dependent, cell sorting, counting, and extraction processes should be performed at low temperature (usually at $4^{\circ} \mathrm{C}$ ).

\section{Step 2: analysis}

Metabolomics approaches are an evolution of classical biochemistry ${ }^{49}$ by permitting the assessment of hundreds to thousands of small-molecule compounds in a routine analysis. In addition to expanding the number of molecules profiled in a metabolomics analysis, advances in nuclear magnetic resonance (NMR) and mass spectrometry (MS) techniques have improved the limits of detection down to the low femtomole range (Fig. 1B).

NMR has been the technique of choice for pioneering experiments on blood cell metabolism under control ${ }^{34}$ and storage conditions. ${ }^{50}$ While this technique has lower sensitivity than MS by up to 100 -fold, NMR offers the advantage of not requiring chromatographic separation of compounds before detection. This in turn limits the number of compounds that are usually assayed in a routine NMR analysis. Furthermore, compounds are often categorized by specific classes (e.g., TCA cycle, glycolysis) due to the difficult resolution of chemical isomers through magnetic resonance. However, absolute quantification of specific highabundance compounds is often more straightforward or rapid with NMR approaches. Through tracing experiments that monitor metabolic fluxes of heavy carbon-labeled glucose at Positions 1 and $2\left({ }^{13} \mathrm{C}_{1,2}\right.$-glucose - a detail of expected isotopologue distribution in glycolysispentose phosphate pathway and serine biosynthesis and/or transamination reactions in glucose labeling experiments is provided in Fig. 2), NMR has been a pivotal technique used to study the oxygen-dependent metabolic modulation in RBCs. ${ }^{51,52}$ The established model posits that low oxygen levels promote deoxyhemoglobin binding to the Nterminal cytosolic domain of Band 3, thereby displacing and activating otherwise bound and/or inhibited glycolytic enzymes. In so doing, low oxygen saturation ultimately promotes energy metabolism, while high oxygen saturation results in the inhibition of late glycolytic enzymes and the activation of the antioxidant pentose phosphate pathway that generates NADPH and affects glutathione homeostasis.

MS analyses have enhanced the scope of blood cell metabolomics, especially using the latest-generation quadrupole orbitrap high-sensitivity and high-resolution instruments. 
Though expanding metabolic coverage in comparison to NMR (Fig. 1C), routine analyses are usually more time-consuming due to the upstream chromatographic separation of small molecule metabolites using either hydrophilic interaction or reversed-phase chromatography, for water-soluble or lipophilic compounds, respectively (Fig. 1D). Indeed, the number of samples amenable to routine studies has been constrained by time-consuming analyses and represents a major limitation for the application of omics technologies, especially proteomics, to transfusion medicine. These limitations have recently been overcome with the introduction of ultra-high-performance liquid chromatography, improvements in gas chromatography, faster-scanning high-resolution MS instruments, and the application of spiked-in standards. By taking advantage of these technologic improvements, untargeted analyses covering up to several thousand features in a single run can be performed in 3minute runs. ${ }^{48}$ Now, hundreds of samples per day can be routinely tested for discoverymode analyses and screened for absolute quantitation of a subset of compounds through untargeted and targeted ultra-high-performance liquid chromatography-MS technologies, respectively. In addition, MS metabolomics with high-resolution instruments (hybrid quadrupole time-of-flight or orbitraps) enable accurate determination of isotopic patterns, a prerequisite necessary for flux balance analyses and high-confidence metabolite identification.

Historically, absolute quantitation of compounds of interest was performed using targeted approaches through quadrupole MS systems to specifically monitor up to approximately 250 compounds for targeted analysis. By spiking in known amounts of stable isotope-labeled compounds (e.g., ${ }^{13} \mathrm{C}$-glucose, ${ }^{13} \mathrm{C}$-amino acids) and determining the peak area ratios of heavy exogenous and/or light endogenous isotopologues, absolute quantitation has been streamlined for high-throughput metabolomics analyses merging the advantages of discovery mode approaches and the quantitative accuracy of targeted ones.

\section{Step 3: bioinformatics and/or post hoc elaboration: compound identification and flux balance analysis}

Upon acquisition of the data (post hoc), whether through NMR or through MS, data analysis using bioinformatics approaches is required to identify metabolites. While software packages for data analysis in NMR have been extensively reviewed, ${ }^{53}$ we will try to describe a streamlined workflow to assign and quantify metabolites from raw MS data. Each mass spectrum is characterized by three variables: an accurate intact mass, a chromatographic retention time (when the compound elutes from the chromatographic column), and an isotopic pattern. Additional information may be derived from fragmentation of the compound during data acquisition using an approach known as tandem MS or MS/MS. This approach provides an additional level of confidence in metabolite assignment by detecting the fragments arising from the collision of the ionized molecule with a gas (often nitrogen or helium). These four pieces of information are then elaborated through ad hoc software to interrogate in-house or freely available public databases (e.g., Metlin, human metabolon database, KEGG database, ChemSpider, NIST) allowing for the heuristic assignment of a metabolite to a given peak. ${ }^{54}$ Classical chemistry rules such as Lewis and Senior rules apply. Unambiguous metabolite identification is based on these rules, especially in discovery mode approaches when novel "features" may be associated to storage duration, for example. 
In Fig. 1E a simplified example is provided for lactate. MS analyses provide accurate intact mass and isotopic patterns, which are necessary to determine the chemical formula of a given compound. The first (monoisotopic) peak is representative of molecules of a given compound that contain only the light isotopes of the constituting atoms (e.g., carbon, nitrogen). For molecules with a single charge, a second peak that is 1.0034 amu heavier than the monoisotopic peak can usually be observed. The additional mass in the heavier peak results from the presence of ${ }^{13} \mathrm{C}$, which weighs 1.0034 amu more than ${ }^{12} \mathrm{C}$. Thus, this second peak represents molecules of the same compound that have at least one heavy ${ }^{13} \mathrm{C}$ atom. The natural abundance of ${ }^{13} \mathrm{C}$, which describes the probability that any carbon in a molecule will be ${ }^{13} \mathrm{C}$, is approximately $1.1 \%$. Accordingly, the ratio of the monoisotopic to the "+1.0034 amu" peak can determine the number of carbon atoms present in that molecule. In this example, lactate has three carbon atoms and therefore the ratio is approximately $3.3 \%$, as indicated in Fig. 1E.

Once a peak is identified as a given metabolite, quantitation is performed by integrating the area underneath that peak. If heavy labeled standards for the metabolite have been added to the extraction buffer, relative peak areas of heavy and light peaks for a given compound are used to determine absolute quantification. Alternatively, peak areas can be compared to external calibration curves, which are calculated by running a dilution series of purified standards preferably constituted in a comparable matrix using the same analytical conditions. However, it should be noted that the majority of metabolomics studies rely on exploratory relative quantitation. One of the main reasons underlying this application is that the resolution of thousands of peaks does not result in the identification of thousands of metabolites. This discrepancy is due to the fact that these peaks can result from factors such as in source fragmentation and adduct formation (for example with salts). However, a new generation of MS data analysis software can correct for these issues, at least for relative quantitation, to identify which peaks are parent metabolites..$^{55,56}$

Incubation with heavy labeled substrates (e.g., uniformly labeled glucose) allows for the monitoring of metabolic fluxes through particular pathways. This approach can indirectly determine enzyme activities in time course analysis by calculating the rapidity of heavy labeled substrate consumption and product generation. Although flux analyses have become one method of choice in the field of cancer research, ${ }^{57}$ their application in transfusion medicine is limited yet appears to be promising. ${ }^{58}$

\section{Step 4: statistical analysis}

Handling and interpretation of big omics data can be cumbersome and overwhelming. Clearly, the capacity of metabolomics to generate an immense amount of data on hundreds of samples offers a unique systemwide perspective for new understanding and hypothesis generation. This benefit, though, can generate a bioinformatics hurdle that requires a level of expertise that many labs lack. ${ }^{59}$ As such, strategies to disseminate results in a more easily understandable manner have been designed. Data elaboration and visualization strategies such as heat maps, hierarchical clustering analyses, and principal component analyses have been envisaged to provide a simplified overview of the results at a glance. ${ }^{60,61}$ These approaches allow for the use of hundreds of quantitative metabolomics data points (e.g., 
metabolite levels during storage of RBCs) as loading variables to determine two to three principal components that explain a given percentage of the total variability across samples. By sorting for metabolites with the highest weights on sample variability, this statistical analysis can quickly highlight the main metabolic variables that change across different conditions (storage duration, donor variability, effect of pathogen inactivation, etc.). Through the clustering of samples either in a totally unsupervised (hierarchical clustering analysis, principal component analysis) or a partially supervised way (partial least-square discriminant analysis), the investigator can infer how similar one sample group is to another from a metabolic perspective. ${ }^{62}$ Though merely descriptive, these types of analyses provide discrimination of individual or multiple metabolites for subsequent correlative or mechanistic analysis (e.g., identification of a key pathway that is affected specifically by one treatment or condition).

\section{DESCRIPTIVE METABOLOMICS IN DESIGN AND TESTING OF TRANSFUSION MEDICINE PRODUCTS}

Omics studies in the field of transfusion medicine have been often criticized for their mere observational and descriptive nature. In this section, we will provide a general overview of what metabolomics studies have contributed to the field and the potential that this technology holds for the advancement of transfusion practices (Table 1).

\section{Storage solutions}

As previously discussed, the early success in transfusion medicine and the pioneering classic biochemistry studies have been deeply intertwined. ASs have been designed and optimized through this connubium. As metabolomics is often referred to as the consequential next step in the field of biochemistry, it is no wonder that NMR_50,63 or MS-based metabolomics technologies have been largely exploited to investigate the RBC metabolic storage lesion in presence of different ASs, including SAGM, AS-1, AS-3, AS-5, AS-7, and PAGGGM. 22,64-71 While the most relevant information on energy metabolism (especially ATP, DPG, and lactate levels) could be obtained through spectrophotometric approaches, metabolomics analyses have offered a kinetic perspective by revealing an initial increase and then progressive decrease in the activity of the pentose phosphate pathway after the second week of storage. Indeed, the activity of the rate-limiting enzyme of the pentose phosphate pathway, glucose 6-phosphate dehydrogenase (G6PDH) is pH dependent. Besides, decreases in G6PDH activity are observed at the end of the storage period, although these findings are controversial $^{72,73}$ (Figs. 3A and 3B). Evaluation of G6PDH activity during RBC storage has only been evaluated at $37^{\circ} \mathrm{C}$ or similar temperature and not at the $4^{\circ} \mathrm{C}$ storage condition, which makes metabolomics assessment rather than indirect enzymatic activity assays more relevant to directly monitor metabolic fluxes under blood bank conditions. Correspondingly, progressive accumulation of oxidative stress markers such as oxidized lipids (e.g., 8isoprostane and eicosanoids) $)^{68,74}$ have been documented in RBCs and supernatants in different ASs. ${ }^{65,66,68}$ The rate of glutathione synthesis significantly declines during routine storage, ${ }^{63,68,75,76}$ while oxoproline accumulates as a dead-end product of the gammaglutamyl cycle because of the lack of oxoprolinase activity in mature RBCs. Metabolomics studies have also helped in appreciating the effect of the storage lesion on purine 
homeostasis, as adenosine, AMP, IMP, and hypoxanthine have been found to significantly accumulate during storage in all tested additives. ${ }^{64-71}$ This finding is relevant due to the emerging role of purinergic signaling, both at the membrane and at the intracellular level, in modulating metabolic and structural homeostasis of the healthy and sickling RBC. ${ }^{77}$

Of note, metabolic pathway analysis has revealed a general overlap for metabolic profiles of RBCs stored in different ASs, although energy and redox homeostasis-related variables have been found to be better preserved in low-chloride, high-bicarbonate, or alkaline solutions, such as PAGGGM, AS-3, and AS-7, although paired studies are still awaited. The proposed rationale behind these observations is that high-bicarbonate and low-chloride additives, by either directly affecting the $\mathrm{pH}$ or promoting the so-called chloride shift, promote intracellular alkalinization, which counteracts $\mathrm{pH}$ decline observed during storage of RBCs and thus preserves the activity of key enzymes such as phosphofructokinase and biphosphoglycerate mutase for longer periods ${ }^{20,21}$ (Figs. 3B and 3C).

\section{Donor variability}

As metabolic profiles are a key aspect of cellular phenotypes, they are affected by all upstream systems, including the genomic background, gene expression profiles, and environmental stimuli. ${ }^{78}$ Interdonor variability might thus be a significant confounder in the small-scale metabolomics studies performed to date, where the number of observed variables is usually larger than the tested cohort. To overcome this hurdle, metabolomics analyses have been performed on RBCs from animal models ${ }^{39}$ and twin studies, ${ }^{76,79,80}$ the latter of which stemmed from classic family studies on heritability of ATP levels by Dern and colleagues. ${ }^{81}$ These studies confirmed and expanded on the potential mechanistic role of metabolites involved in oxidative lesions of stored RBCs, such as glutathione, 5-oxoproline, hypoxanthine-urate, and oxidized lipids. Of note, the appreciation of altered homeostasis in the purine catabolism pathway, leading to the generation of urate in humans and allantoinallantoate in mice ${ }^{39,68}$ has fostered and supported the formulation of a potential role for donor-specific prestorage urate levels in attenuating oxidative lesion during routine storage of RBCs. ${ }^{82}$ Future studies should address whether metabolic lesions may be further exacerbated in certain categories of routine donors with enzymopathies compromising their redox defenses, such as G6PDH-deficient subjects. ${ }^{83}$

\section{Alternative additives and/or rejuvenation solutions}

Despite donor- and AS-dependent variability, storage of RBCs characteristically results in the progressive impairment of energy metabolism and accumulation of oxidative stress markers at the protein, lipid, and small-molecule level (Fig. 4-as we, among others, have reviewed). ${ }^{6}$ Although the depletion of ATP and DPG observed during RBC storage are rapidly restored during the first 1 to 3 days after transfusion, ${ }^{84}$ it has long been appreciated that the energy-less RBC may be more susceptible to removal from the bloodstream, ${ }^{85}$ potentially impairing in vivo survival and thus the effectiveness of the transfusion therapy. Attempts have been made to restore RBC energy metabolism through washing and resuspension in rejuvenation solutions. ${ }^{86}$ While classic metabolic measurements looked promising, with maximal benefit obtained when rejuvenation was performed within a 2- to 
4-storage-week window, ${ }^{86}$ no in-depth metabolomics study has been hitherto used to elaborate upon these findings.

Many groups have proposed alternatives to restore redox imbalance by supplementing storage solutions with antioxidants, such as vitamin C, either alone or in combination with the glutathione precursor $\mathrm{N}$-acetylcysteine. ${ }^{87,88}$ Others have proposed supplementation of alternative antioxidants, such as serotonin. ${ }^{89}$ Although results indicate a partial improvement in oxidative stress-related variables such as oxidized peroxiredoxin-2 dimers, ${ }^{88}$ better results have been obtained by implementing alkaline ASs. ${ }^{90}$ In addition, dehydroascorbate (oxidized form of vitamin C) competes with glucose for its uptake by human RBCs at the glucose transporter level, ${ }^{91}$ resulting in promotion of redox homeostasis at the expense of energy metabolism. ${ }^{88}$

Alternatively, Yoshida and colleagues ${ }^{92,93}$ and Zolla and colleagues ${ }^{94,95}$ have independently proposed anaerobic storage of RBCs as a strategy to exploit the above-mentioned oxygendependent metabolic modulation phenomenon ${ }^{33,52,96}$ in RBCs to promote energy metabolism, while concomitantly removing a key contributor to prooxidant reactions. Metabolomics studies have been performed to confirm that energy metabolism-related variables are improved by anaerobic storage at the expense of the pentose phosphate pathway and general antioxidant potential, ${ }^{94}$ consistent with previous in vitro studies. ${ }^{96,97}$ More recently, we demonstrated a role for anaerobiosis versus anaerobiosis in presence of $\mathrm{CO}_{2}$ in modulating metabolic responses upon deoxygenation ${ }^{98}$ (Fig. 5). It is worth pointing out that, due to biophysical constraints, complete anaerobiosis is unlikely to be achieved without an extensive manipulation of the sample. While complete anaerobiosis may be logistically challenging to achieve and preserve during routine processing of blood components, advanced engineered devices might enable straightforward removal of a significant oxygen percentage and pave the way for the hypoxic storage of RBCs or other blood products. In this view, future studies will be performed to determine the optimal hypoxic conditions, that is, the $\mathrm{O}_{2}$ and $\mathrm{CO}_{2}$ concentration ranges necessary to promote the highest metabolic advantages (ATP and DPG preservation, preserved redox homeostasis).

\section{Cell processing}

Metabolomics has been increasingly used as a surrogate indicator of the effects of cell processing on storage quality. For example, metabolomics analyses have recently been performed to compare apheresis and buffy coat PLT concentrates. ${ }^{99,100}$ Through targeted MS-based metabolomics, Paglia and colleagues ${ }^{99,100}$ analyzed 150 to 174 variables during seven to eight different time points in apheresis and buffy coat PLTs under routine blood banking conditions. Apheresis PLTs were characterized by an early activation phenotype, as mirrored by increased metabolic activity in glycolysis and the Krebs cycle. Significant interdonor variability was observed, accounting for the low reproducibility of apheresis PLT concentrates. ${ }^{99}$ Bioinformatic analysis of metabolomics data also revealed the presence of three main metabolic stages, characterized by 1) active glycolysis, pentose phosphate pathway, and glutathione metabolism and down regulation of the Krebs cycle (Days 0-3); 2) a more active TCA cycle as well as increased purine metabolism (Days 4-6); and 3) a faster 
decay of cellular metabolism (Days 7-10-longer than the shelf life of PLT concentrates and thus outside the clinically relevant range). ${ }^{100}$

Patel, Roback, and colleagues ${ }^{101}$ recently adopted metabolomics technologies to show that gamma irradiation accelerates metabolic derangement of stored RBCs. Metabolomics lesion upon treatment of RBC or PLT concentrates after treatment with other pathogen reduction technology has not been investigated yet. Future applications of semitargeted metabolomics approaches could be targeted at testing the formulation of blood bags with plasticizers other than diethylhexyl-hydroxyphthalate ${ }^{102}$ or additional areas associated with safety of blood products, collection, processing, and storage strategies that have the potential to affect either donors or recipients.

\section{FROM DESCRIPTIVE TO CORRELATIVE: METABOLOMICS AND GOLDEN STANDARDS OF TRANSFUSION MEDICINE}

Metabolomics studies performed in the field of transfusion medicine have primarily focused on correlative associations and therefore are descriptive. To have a larger impact on the field, future studies should be designed with increased number of biologic replicates, and data should be amenable to correlative or mechanistic analyses. Correlative analysis of metabolite levels during storage duration and gold standards of transfusion (such as 24-hr in vivo survival and hemolysis) are a necessary step if metabolomics is to become a surrogate or complementary quality control tool for the transfusion medicine expert. While preliminary correlative evidence between metabolic profiles and hemolysis has been produced, ${ }^{103}$ correlative analysis between 24-hour in vivo survival and storage metabotypes (metabolic phenotypes) is still missing.

\section{SYSTEMS BIOLOGY AND METABOLOMICS AS A TOOL TO BUILD IN SILICO PREDICTIVE MODELS}

Since correlative evidence about the link between metabolites other than ATP and DPG on transfusion quality outcomes was produced, a standing question in the field has been whether storage conditions might be altered in silico to predict metabolic profiles and thus speed up the design and testing of alternative ASs or storage strategies. ${ }^{43,99,104}$ Computer models of RBC and PLT metabolic maps have been refined over the years. ${ }^{43,44}$ However, since models can only be as good as the data that feed them, it is reasonable to anticipate that large-scale high-throughput metabolomics will soon speed up the optimization and thus the predictive capacity of these models, with obvious benefits to the field.

\section{CONCLUDING REMARKS}

In the next 5 years, the field of transfusion medicine can anticipate advances in understanding of donor and recipient safety, as well as the effectiveness of the transfusion therapy. ${ }^{5}$ Similar to the three stages of Hegel philosophy, metabolomics has proved its immediate usefulness for descriptive purposes ("in itself"). An "aufhebung" ("preservation and change") is necessary for metabolomics to become even more powerful than an expensive descriptive tool in transfusion medicine. Here we envisage a correlative stage 
("out of itself"), when metabolic phenotypes will be correlated to transfusion outcomes, and a third stage ("in and for itself"), when metabolomics will meet systems biology to become a predictive tool. If these "romantic strides" will be taken, metabolomics analyses could potentially become surrogate markers of blood cell storage quality and contribute new significant advances to our understanding of RBC physiology and storability. Predictably, these steps will speed up the design and testing of alternative ASs and storage strategies.

\section{References}

1. Rous P, Turner JR. The preservation of living red blood cells in vitro. J Exp Med. 1916; 23:219-37. [PubMed: 19867981]

2. Blood safety and availability [Internet]. Geneva: WHO; 2015. Available from: http://www.who.int/ entity/mediacentre/factsheets/fs279/en/index.html [2015 Sep 23]

3. Holst LB, Petersen MW, Haase N, et al. Restrictive versus liberal transfusion strategy for red blood cell transfusion: systematic review of randomised trials with meta-analysis and trial sequential analysis. BMJ. 2015; 350:h1354. [PubMed: 25805204]

4. Carson JL, Sieber F, Cook DR, et al. Liberal versus restrictive blood transfusion strategy: 3-year survival and cause of death results from the FOCUS randomised controlled trial. Lancet. 2015; 385:1183-9. [PubMed: 25499165]

5. Spitalnik SL, Triulzi D, Devine DV, et al. 2015 proceedings of the National Heart, Lung, and Blood Institute's State of the Science in Transfusion Medicine symposium. Transfusion. 2015; 55:228290. [PubMed: 26260861]

6. D’Alessandro A, Kriebardis AG, Rinalducci S, et al. An update on red blood cell storage lesions, as gleaned through biochemistry and omics technologies. Transfusion. 2015; 55:205-19. [PubMed: 25130459]

7. Hess JR. Red cell storage. J Proteomics. 2010; 73:368-73. [PubMed: 19914410]

8. Zimring JC. Established and theoretical factors to consider in assessing the red cell storage lesion. Blood. 2015; 125:2185-90. [PubMed: 25651844]

9. Mollison PL. The introduction of citrate as an anticoagulant for transfusion and of glucose as a red cell preservative. Br J Haematol. 2000; 108:13-8. [PubMed: 10651719]

10. Greenwalt TJ. A short history of transfusion medicine. Transfusion. 1997; 37:550-63. [PubMed: 9149783]

11. Hess JR. An update on solutions for red cell storage. Vox Sang. 2006; 91:13-9. [PubMed: 16756596]

12. Hammarsten, O. Untersuchungen über die Faserstoffgerinnung. Uppsala: Akademische Buchdruckerei; p. 1875

13. Robertson OH. Transfusion with preserved red blood cells. Br Med J. 1918; 1:691-5. [PubMed: 20769077]

14. Högman CF, Hedlund K, Zetterström H. Clinical usefulness of red cells preserved in protein-poor mediums. N Engl J Med. 1978; 299:1377-82. [PubMed: 714116]

15. Högman CF, Hedlund K, Sahleström Y. Red cell preservation in protein-poor media III Protection against in vitro hemolysis. Vox Sang. 1981; 41:274-81. [PubMed: 6798761]

16. Heaton A, Miripol J, Aster R, et al. Use of Adsol preservation solution for prolonged storage of low viscosity AS-1 red blood cells. Br J Haematol. 1984; 57:467-78. [PubMed: 6430332]

17. Simon TL, Marcus CS, Myhre BA, et al. Effects of AS-3 nutrient-additive solution on 42 and 49 days of storage of red cells. Transfusion. 1987; 27:178-82. [PubMed: 3824477]

18. Cicha I, Suzuki Y, Tateishi N, et al. Gamma-ray-irradiated red blood cells stored in mannitoladenine-phosphate medium: rheological evaluation and susceptibility to oxidative stress. Vox Sang. 2000; 79:75-82. [PubMed: 11054044]

19. Walker WH, Netz M, Gänshirt KH. [49 day storage of erythrocyte concentrates in blood bags with the PAGGS-mannitol solution]. Beitr Zur Infusionstherapie Contrib Infus Ther. 1990; 26:55-9. German. 
20. Hess JR, Hill HR, Oliver CK, et al. Alkaline CPD and the preservation of RBC 2,3-DPG. Transfusion. 2002; 42:747-52. [PubMed: 12147028]

21. Hess JR, Rugg N, Joines AD, et al. Buffering and dilution in red blood cell storage. Transfusion. 2006; 46:50-4. [PubMed: 16398730]

22. Sparrow RL. Time to revisit red blood cell additive solutions and storage conditions: a role for “omics” analyses. Blood Transfus. 2012; 10(Suppl 2):s7-11. [PubMed: 22890271]

23. Rapoport TA, Heinrich R, Jacobasch G, et al. A linear steady-state treatment of enzymatic chains. A mathematical model of glycolysis of human erythrocytes. Eur J Biochem FEBS. 1974; 42:10720.

24. Heinrich R, Rapoport TA. Mathematical analysis of multienzyme systems. II. Steady state and transient control. Biosystems. 1975; 7:130-6. [PubMed: 125616]

25. Heinrich R, Rapoport SM, Rapoport TA. Metabolic regulation and mathematical models. Prog Biophys Mol Biol. 1977; 32:1-82. [PubMed: 343173]

26. Rapoport TA, Otto M, Heinrich R. An extended model of the glycolysis in erythrocytes. Acta Biol Med Ger. 1977; 36:461-8. [PubMed: 145774]

27. Schauer M, Heinrich R, Rapoport SM. Mathematical modelling of glycolysis and adenine nucleotide metabolism of human erythrocytes. I. Reaction-kinetic statements, analysis of in vivo state and determination of starting conditions for in vitro experiments. Acta Biol Med Ger. 1981; 40:1659-82. German. [PubMed: 6285649]

28. Brumen M, Heinrich R. A metabolic osmotic model of human erythrocytes. Biosystems. 1984; 17:155-69. [PubMed: 6525455]

29. Holmsen H. Energy metabolism and platelet responses. Vox Sang. 1981; 40(Suppl 1):1-7.

30. Holmsen H. Platelet metabolism and activation. Semin Hematol. 1985; 22:219-40. [PubMed: 2994234]

31. Holzhütter HG, Jacobasch G, Bisdorff A. Mathematical modelling of metabolic pathways affected by an enzyme deficiency. A mathematical model of glycolysis in normal and pyruvate-kinasedeficient red blood cells. Eur J Biochem. 1985; 149:101-11. [PubMed: 3996397]

32. Lew VL, Bookchin RM. Volume, $\mathrm{pH}$, and ion-content regulation in human red cells: analysis of transient behavior with an integrated model. J Membr Biol. 1986; 92:57-74. [PubMed: 3746891]

33. Low PS, Rathinavelu P, Harrison ML. Regulation of glycolysis via reversible enzyme binding to the membrane protein, band 3. J Biol Chem. 1993; 268:14627-31. [PubMed: 8325839]

34. Messana I, Misiti F, el-Sherbini S, et al. Quantitative determination of the main glucose metabolic fluxes in human erythrocytes by 13C- and 1H-MR spectroscopy. J Biochem Biophys Methods. 1999; 39:63-84. [PubMed: 10344501]

35. Lee ID, Palsson BO. A comprehensive model of human erythrocyte metabolism: extensions to include pH effects. Biomed Biochim Acta. 1990; 49:771-89. [PubMed: 2082921]

36. Jamshidi N, Wiback SJ, Palsson B BØ. In silico model-driven assessment of the effects of single nucleotide polymorphisms (SNPs) on human red blood cell metabolism. Genome Res. 2002; 12:1687-92. [PubMed: 12421755]

37. Jamshidi N, Palsson BØ. Systems biology of the human red blood cell. Blood Cells Mol Dis. 2006; 36:239-47. [PubMed: 16533612]

38. Duc G, Engel K. Effect of 2,3-DPG concentration on hemoglobin-oxygen affinity of whole blood. Scand J Clin Lab Invest. 1969; 24:405-12. [PubMed: 5383333]

39. Zimring JC, Smith N, Stowell SR, et al. Strain-specific red blood cell storage, metabolism, and eicosanoid generation in a mouse model. Transfusion. 2014; 54:137-48. [PubMed: 23721209]

40. D'Alessandro A, Righetti PG, Zolla L. The red blood cell proteome and interactome: an update. J Proteome Res. 2010; 9:144-63. [PubMed: 19886704]

41. Goodman SR, Daescu O, Kakhniashvili DG, et al. The proteomics and interactomics of human erythrocytes. Exp Biol Med (Maywood). 2013; 238:509-18. [PubMed: 23856902]

42. Burkhart JM, Vaudel M, Gambaryan S, et al. The first comprehensive and quantitative analysis of human platelet protein composition allows the comparative analysis of structural and functional pathways. Blood. 2012; 120:e73-82. [PubMed: 22869793] 
43. Bordbar A, Jamshidi N, Palsson BO. iAB-RBC-283: a proteomically derived knowledge-base of erythrocyte metabolism that can be used to simulate its physiological and patho-physiological states. BMC Syst Biol. 2011; 5:110. [PubMed: 21749716]

44. Thomas A, Rahmanian S, Bordbar A, et al. Network reconstruction of platelet metabolism identifies metabolic signature for aspirin resistance. Sci Rep. 2014; 4:3925. [PubMed: 24473230]

45. Zimring JC. Widening our gaze of red blood storage haze: a role for metabolomics. Transfusion. 2015; 55:1139-42. [PubMed: 26074173]

46. Mushtaq MY, Choi YH, Verpoorte R, et al. Extraction for metabolomics: access to the metabolome. Phytochem Anal PCA. 2014; 25:291-306. [PubMed: 24523261]

47. Sysi-Aho M, Katajamaa M, Yetukuri L, et al. Normalization method for metabolomics data using optimal selection of multiple internal standards. BMC Bioinformatics. 2007; 8:93. [PubMed: 17362505]

48. Nemkov T, D'Alessandro A, Hansen KC. Three-minute method for amino acid analysis by UHPLC and high-resolution quadrupole orbitrap mass spectrometry. Amino Acids. 2015; 47:2345-57. [PubMed: 26058356]

49. D'Alessandro A, Giardina B, Gevi F, et al. Clinical metabolomics: the next stage of clinical biochemistry. Blood Transfus. 2012; 10:s19-24. [PubMed: 22890264]

50. Messana I, Ferroni L, Misiti F, et al. Blood bank conditions and RBCs: the progressive loss of metabolic modulation. Transfusion. 2000; 40:353-60. [PubMed: 10738039]

51. Rogers SC, Ross JG, d'Avignon A, et al. Sickle hemoglobin disturbs normal coupling among erythrocyte $\mathrm{O} 2$ content, glycolysis, and antioxidant capacity. Blood. 2013; 121:1651-62. [PubMed: 23297128]

52. Castagnola M, Messana I, Sanna MT, et al. Oxygen-linked modulation of erythrocyte metabolism: state of the art. Blood Transfus. 2010; 8:s53-8. [PubMed: 20606750]

53. Izquierdo-García JL, Villa P, Kyriazis A, et al. Descriptive review of current NMR-based metabolomic data analysis packages. Prog Nucl Magn Reson Spectrosc. 2011; 59:263-70. [PubMed: 21920221]

54. Kind T, Fiehn O. Seven golden rules for heuristic filtering of molecular formulas obtained by accurate mass spectrometry. BMC Bioinformatics. 2007; 8:105. [PubMed: 17389044]

55. Smith CA, Want EJ, O'Maille G, et al. XCMS: processing mass spectrometry data for metabolite profiling using nonlinear peak alignment, matching, and identification. Anal Chem. 2006; 78:779_ 87. [PubMed: 16448051]

56. Broeckling CD, Afsar FA, Neumann S, et al. RAMClust: a novel feature clustering method enables spectral-matching-based annotation for metabolomics data. Anal Chem. 2014; 86:6812-7. [PubMed: 24927477]

57. Buescher JM, Antoniewicz MR, Boros LG, et al. A roadmap for interpreting (13)C metabolite labeling patterns from cells. Curr Opin Biotechnol. 2015; 34:189-201. [PubMed: 25731751]

58. D'Alessandro A, Slaughter AL, Peltz ED, et al. Trauma/hemorrhagic shock instigates aberrant metabolic flux through glycolytic pathways, as revealed by preliminary (13)C-glucose labeling metabolomics. J Transl Med. 2015; 13:253. [PubMed: 26242576]

59. Shulaev V. Metabolomics technology and bioinformatics. Brief Bioinform. 2006; 7:128-39. [PubMed: 16772266]

60. Bartel J, Krumsiek J, Theis FJ. Statistical methods for the analysis of high-throughput metabolomics data. Comput Struct Biotechnol J. 2013; 4:e201301009. [PubMed: 24688690]

61. Xia J, Sinelnikov IV, Han B, et al. MetaboAnalyst 3.0-making metabolomics more meaningful. Nucleic Acids Res. 2015; 43:W251-7. [PubMed: 25897128]

62. Korman A, Oh A, Raskind A, et al. Statistical methods in metabolomics. Methods Mol Biol. 2012; 856:381-413. [PubMed: 22399468]

63. Pertinhez TA, Casali E, Lindner L, et al. Biochemical assessment of red blood cells during storage by (1)H nuclear magnetic resonance spectroscopy. Identification of a biomarker of their level of protection against oxidative stress. Blood Transfus. 2014; 12:548-56. [PubMed: 24960643]

64. Gevi F, D’Alessandro A, Rinalducci S, et al. Alterations of red blood cell metabolome during cold liquid storage of erythrocyte concentrates in CPD-SAGM. J Proteomics. 2012; 76:168-80. [PubMed: 22465715] 
65. D'Alessandro A, Hansen KC, Silliman CC, et al. Metabolomics of AS-5 RBC supernatants following routine storage. Vox Sang. 2015; 108:131-40. [PubMed: 25200932]

66. D'Alessandro AD, D'Amici GM, Vaglio S, et al. Time-course investigation of SAGM-stored leukocyte-filtered red blood cell concentrates: from metabolism to proteomics. Haematologica. 2012; 97:107-15. [PubMed: 21993682]

67. D'Alessandro A, Nemkov T, Hansen KC, et al. Red blood cell storage in additive solution-7 preserves energy and redox metabolism: a metabolomics approach. Transfusion. 2015; 55:295566. [PubMed: 26271632]

68. D'Alessandro A, Nemkov T, Kelher M, et al. Routine storage of red blood cell (RBC) units in additive solution-3: a comprehensive investigation of the RBC metabolome. Transfusion. 2015; 55:1155-68. [PubMed: 25556331]

69. Nishino T, Yachie-Kinoshita A, Hirayama A, et al. Dynamic simulation and metabolome analysis of long-term erythrocyte storage in adenine-guanosine solution. PLoS One. 2013; 8:e71060. [PubMed: 24205395]

70. Roback JD, Josephson CD, Waller EK, et al. Metabolomics of ADSOL (AS-1) red blood cell storage. Transfus Med Rev. 2014; 28:41-55. [PubMed: 24636780]

71. Burger P, Korsten H, De Korte D, et al. An improved red blood cell additive solution maintains 2,3diphosphoglycerate and adenosine triphosphate levels by an enhancing effect on phosphofructokinase activity during cold storage. Transfusion. 2010; 50:2386-92. [PubMed: 20500561]

72. Francis RO, Jhang J, Hendrickson JE, et al. Frequency of glucose-6-phosphate dehydrogenasedeficient red blood cell units in a metropolitan transfusion service. Transfusion. 2013; 53:606-11. [PubMed: 22738400]

73. Korgun DK, Bilmen S, Yesilkaya A. Alterations in the erythrocyte antioxidant system of blood stored in blood bags. Res Commun Mol Pathol Pharmacol. 2001; 109:357-63. [PubMed: 12889518]

74. Silliman CC, Moore EE, Kelher MR, et al. Identification of lipids that accumulate during the routine storage of prestorage leukoreduced red blood cells and cause acute lung injury. Transfusion. 2011; 51:2549-54. [PubMed: 21615744]

75. Whillier S, Raftos JE, Sparrow RL, et al. The effects of long-term storage of human red blood cells on the glutathione synthesis rate and steady-state concentration. Transfusion. 2011; 51:1450-9. [PubMed: 21251007]

76. Van 't Erve TJ, Doskey CM, Wagner BA, et al. Heritability of glutathione and related metabolites in stored red blood cells. Free Radic Biol Med. 2014; 76:107-13. [PubMed: 25108189]

77. Zhang Y, Dai Y, Wen J, et al. Detrimental effects of adenosine signaling in sickle cell disease. Nat Med. 2011; 17:79-86. [PubMed: 21170046]

78. Fiehn O. Metabolomics-the link between genotypes and phenotypes. Plant Mol Biol. 2002; 48(1-2):155-71. [PubMed: 11860207]

79. Van 't Erve TJ, Wagner BA, Martin SM, et al. The heritability of metabolite concentrations in stored human red blood cells. Transfusion. 2014; 54:2055-63. [PubMed: 24601981]

80. Van 't Erve TJ, Wagner BA, Ryckman KK, et al. The concentration of glutathione in human erythrocytes is a heritable trait. Free Radic Biol Med. 2013; 65:742-9. [PubMed: 23938402]

81. Dern RJ, Brewer GJ, Wiorkowski JJ. Studies on the preservation of human blood. II. The relationship of erythrocyte adenosine triphosphate levels and other in vitro measures to red cell storageability. J Lab Clin Med. 1967; 69:968-78. [PubMed: 6025497]

82. Tzounakas VL, Georgatzakou HT, Kriebardis AG, et al. Uric acid variation among regular blood donors is indicative of red blood cell susceptibility to storage lesion markers: a new hypothesis tested. Transfusion. 2015; 55:2659-71. [PubMed: 26175071]

83. Francis RO, Jhang JS, Pham HP, et al. Glucose-6-phosphate dehydrogenase deficiency in transfusion medicine: the unknown risks. Vox Sang. 2013; 105:271-82. [PubMed: 23815264]

84. Stan A, Zsigmond E. The restoration in vivo of 2,3-diphosphoglycerate (2,3-DPG) in stored red cells, after transfusion. The levels of red cells 2,3-DPG. Rom J Intern Med. 2009; 47:173-7. [PubMed: 20067168] 
85. Van Wijk R, van Solinge WW. The energy-less red blood cell is lost: erythrocyte enzyme abnormalities of glycolysis. Blood. 2005; 106:4034-42. [PubMed: 16051738]

86. Meyer EK, Dumont DF, Baker S, et al. Rejuvenation capacity of red blood cells in additive solutions over long-term storage. Transfusion. 2011; 51:1574-9. [PubMed: 21251004]

87. Stowell SR, Smith NH, Zimring JC, et al. Addition of ascorbic acid solution to stored murine red blood cells increases posttransfusion recovery and decreases microparticles and alloimmunization. Transfusion. 2013; 53:2248-57. [PubMed: 23384196]

88. Pallotta V, Gevi F, D'Alessandro A, et al. Storing red blood cells with vitamin C and Nacetylcysteine prevents oxidative stress-related lesions: a metabolomics overview. Blood Transfus. 2014; 12:376-87. [PubMed: 25074788]

89. Amireault P, Bayard E, Launay JM, et al. Serotonin is a key factor for mouse red blood cell survival. PLoS One. 2013; 8:e83010. [PubMed: 24358245]

90. Bayer SB, Hampton MB, Winterbourn CC. Accumulation of oxidized peroxiredoxin 2 in red blood cells and its prevention. Transfusion. 2015; 55:1909-18. [PubMed: 25720945]

91. Sage JM, Carruthers A. Human erythrocytes transport dehydroascorbic acid and sugars using the same transporter complex. Am J Physiol Cell Physiol. 2014; 306:C910-7. [PubMed: 24598365]

92. Yoshida T, Shevkoplyas SS. Anaerobic storage of red blood cells. Blood Transfus. 2010; 8:220-36. [PubMed: 20967163]

93. Yoshida T, AuBuchon JP, Tryzelaar L, et al. Extended storage of red blood cells under anaerobic conditions. Vox Sang. 2007; 92:22-31. [PubMed: 17181587]

94. D'Alessandro A, Gevi F, Zolla L. Red blood cell metabolism under prolonged anaerobic storage. Mol Biosyst. 2013; 9:1196-209. [PubMed: 23426130]

95. Longo V, D’Alessandro A, Zolla L. Deoxygenation of leucofiltered erythrocyte concentrates preserves proteome stability during storage in the blood bank. Blood Transfus. 2014; 12:599-604. [PubMed: 24960654]

96. Rogers SC, Said A, Corcuera D, et al. Hypoxia limits antioxidant capacity in red blood cells by altering glycolytic pathway dominance. FASEB J. 2009; 23:3159-70. [PubMed: 19417084]

97. Yachie-Kinoshita A, Nishino T, Shimo H, et al. A metabolic model of human erythrocytes: practical application of the E-Cell Simulation Environment. J Biomed Biotechnol. 2010; 2010:642420. [PubMed: 20625505]

98. Dumont LJ, D’Alessandro A, Szczepiorkowski ZM, et al. $\mathrm{CO}_{2}$-dependent metabolic modulation in red blood cells stored under anaerobic conditions. Transfusion. 2016; 56:392-403. [PubMed: 26477888]

99. Paglia G, Sigurjónsson ÓE, Rolfsson Ó, et al. Metabolomic analysis of platelets during storage: a comparison between apheresis- and buffy coat-derived platelet concentrates. Transfusion. 2015; 55:301-13. [PubMed: 25156572]

100. Paglia G, Sigurjónsson ÓE, Rolfsson Ó, et al. Comprehensive metabolomic study of platelets reveals the expression of discrete metabolic phenotypes during storage. Transfusion. 2014; 54:2911-23. [PubMed: 24840017]

101. Patel RM, Roback JD, Uppal K, et al. Metabolomics profile comparisons of irradiated and nonirradiated stored donor red blood cells. Transfusion. 2015; 55:544-52. [PubMed: 25330719]

102. Dumont LJ, Baker S, Dumont DF, et al. Exploratory in vitro study of red blood cell storage containers formulated with an alternative plasticizer. Transfusion. 2012; 52:1439-45. [PubMed: 22211692]

103. Van 't Erve TJ, Wagner BA, Martin SM, et al. The heritability of hemolysis in stored human red blood cells. Transfusion. 2015; 55:1178-85. [PubMed: 25644965]

104. Bordbar A, McCloskey D, Zielinski DC, et al. Personalized whole-cell kinetic models of metabolism for discovery in genomics and pharmacodynamics. Cell Syst. 2015; 1:283-92. [PubMed: 27136057]

105. Wither M, Dzieciatkowska M, Nemkov T, et al. Hemoglobin oxidation at functional amino acid residues during routine storage of red blood cells. Transfusion. 2016; 56:421-6. [PubMed: 26426339] 


\section{ABBREVIATIONS}

G6PDH glucose-6-phosphate dehydrogenase

NMR nuclear magnetic resonance 

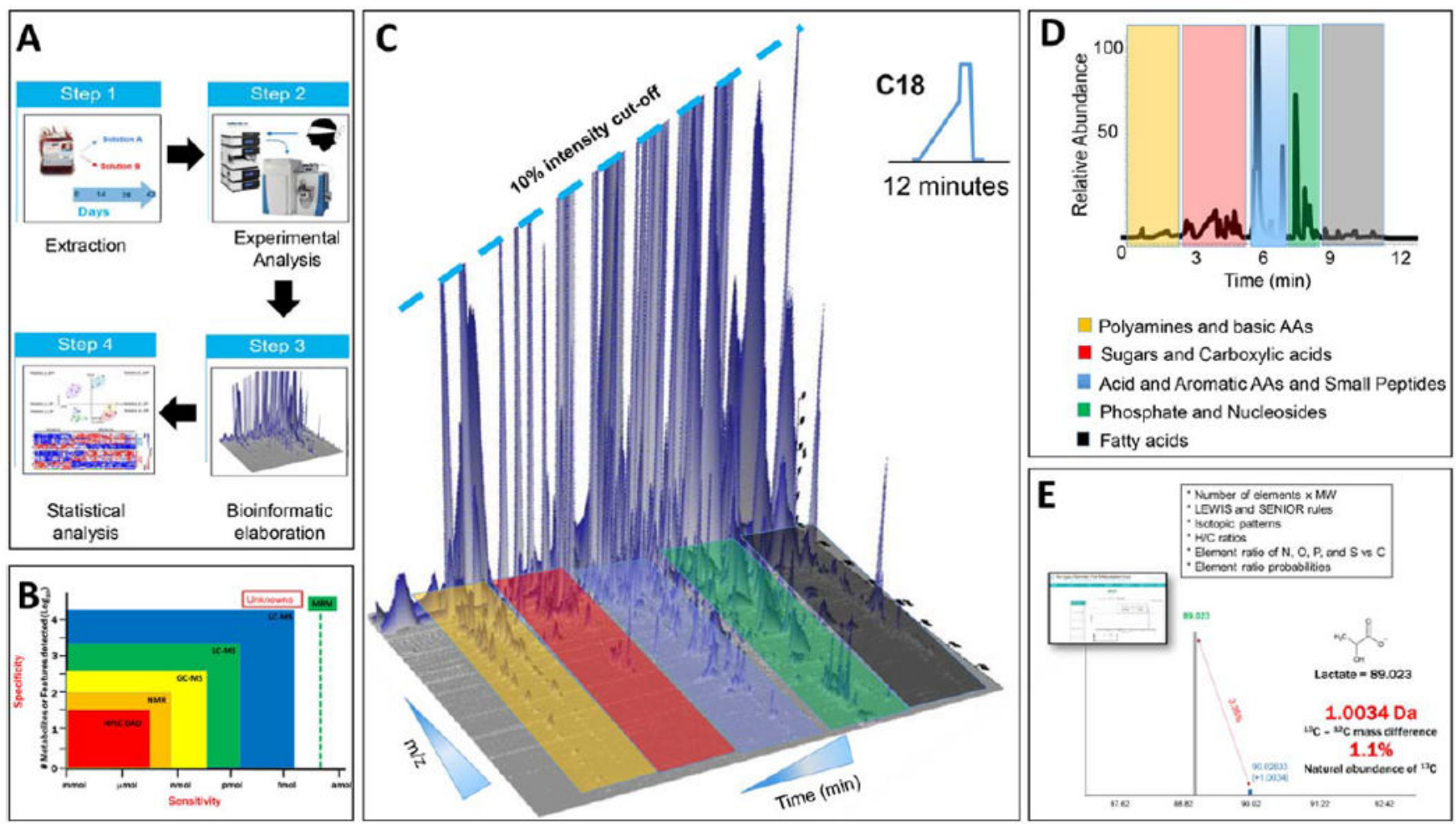

Fig. 1.

(A) Overview of the metabolomics workflow. (B) General sensitivity and specificity attributes for NMR and MS technologies. Targeted MS-based approaches such as multiple reaction monitoring (MRM) increase sensitivity of the assays, at the expense of the total number of compounds monitored in one analysis. (C and D) Representative threedimensional and two-dimensional spectrum of a routine 12-minute run of RBC extracts. (E) Representative schematic of metabolite identity assignment on the basis of accurate intact mass, chromatographic retention times, isotopic patterns, and the seven golden rules for the heuristic determination of compound identifications on the basis of MS profiles. 


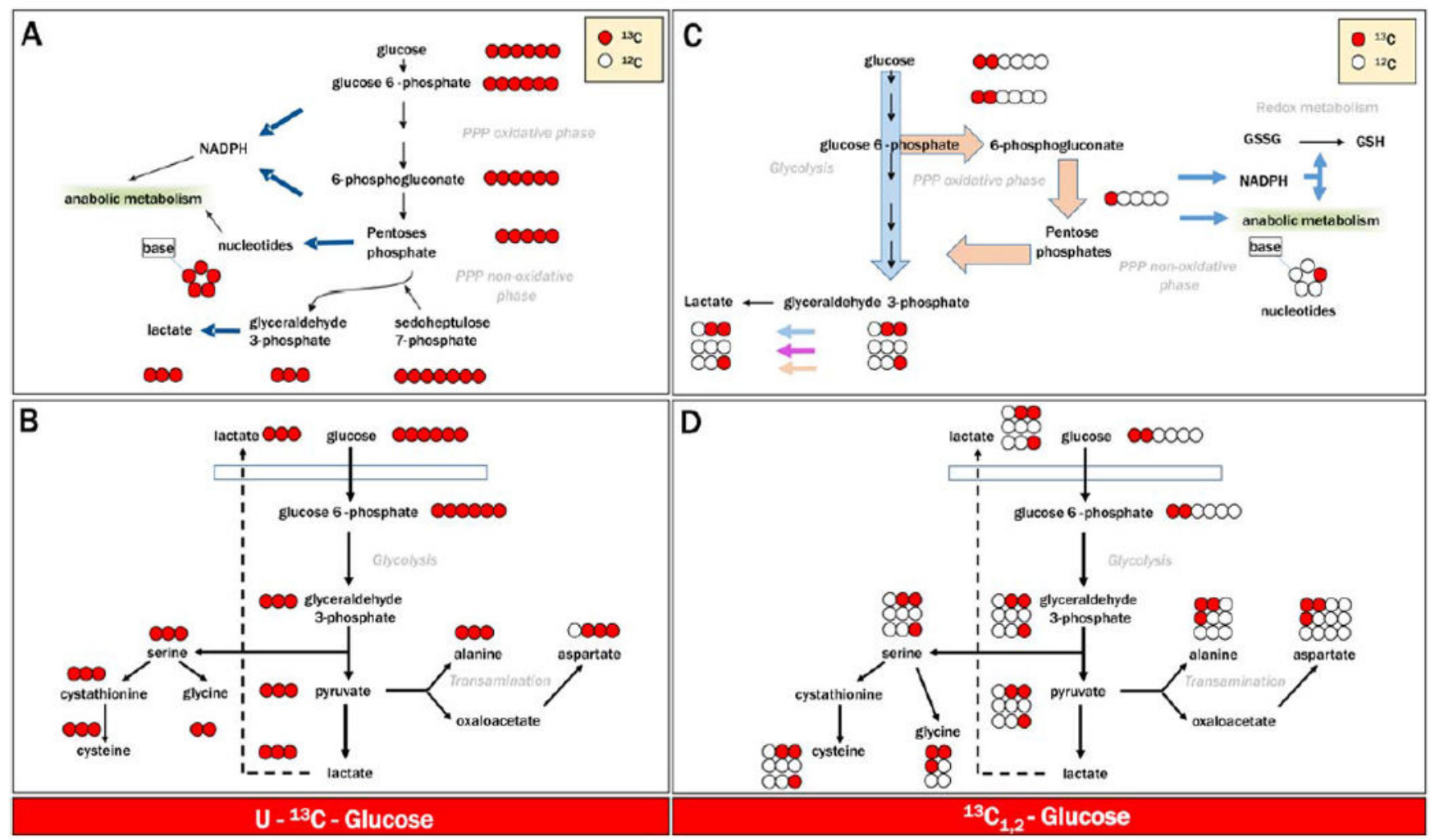

Fig. 2.

Flux balance analysis and tracing experiments upon incubation of blood cell products with heavy labeled substrates has been made amenable to routine analysis by the introduction of state-of-the-art NMR- 50 and MS-based analytical technologies. Here we show four representative examples of isotopologue distributions upon labeling of glycolysis-pentose phosphate pathway and serine biosynthesis-transaminase activity pathway, after incubation of cells with uniformly labeled ${ }^{13} \mathrm{C}_{1-6}$-glucose (A and B) or glucose labeled only at Carbon Positions 1 and $2\left({ }^{13} \mathrm{C}_{1,2}\right.$-glucose- $\mathrm{C}$ and $\left.\mathrm{D}\right)$, respectively. 

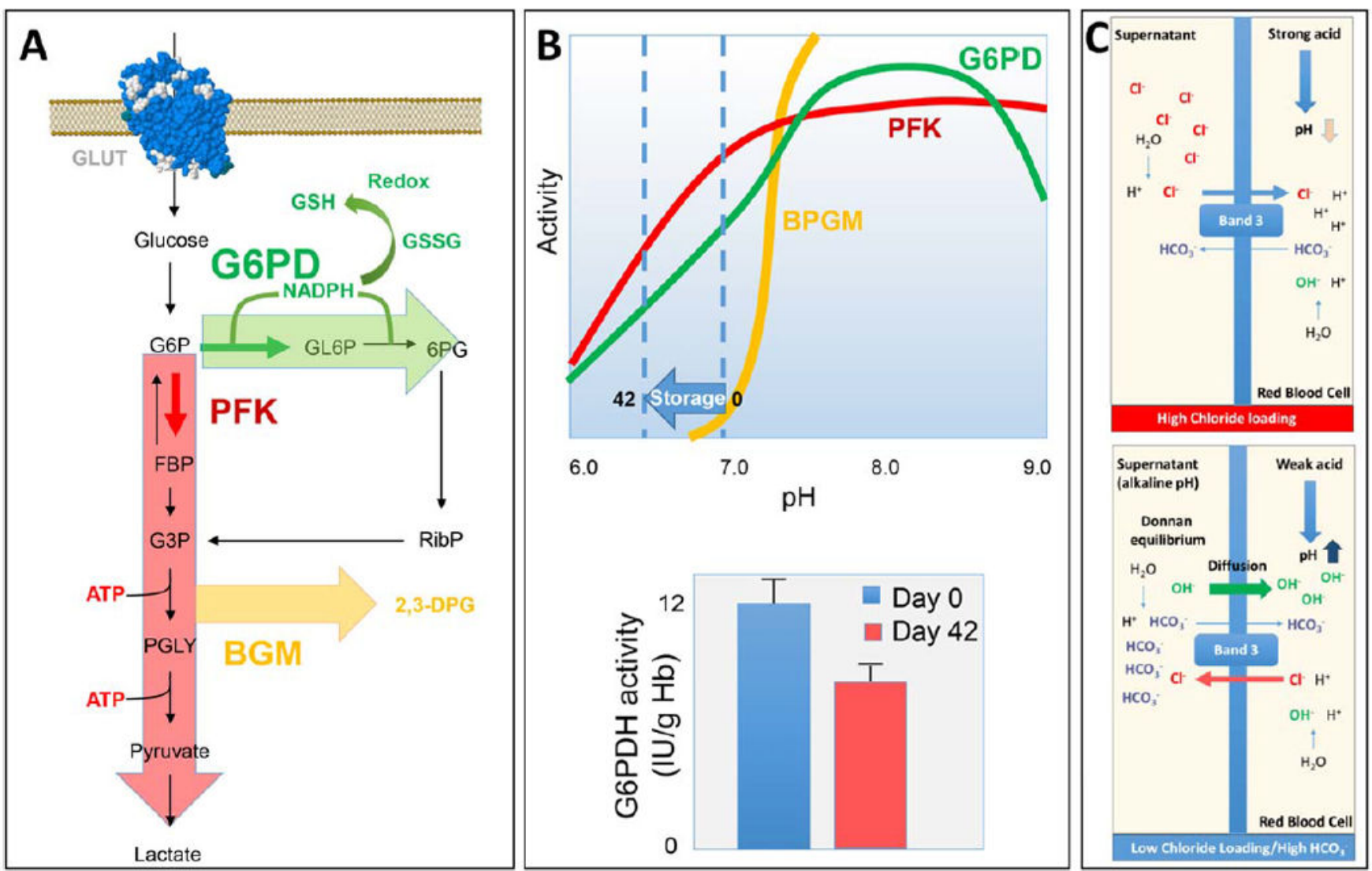

Fig. 3.

(A) Overview of the main glucose oxidation pathways in RBCs. (B) pH dependency of the activity of rate-limiting enzymes of glycolysis, pentose phosphate pathway, and RapoportLuebering shunt are shown. (C) Schematized representation of the combined effect on $\mathrm{pH}$ mediated by the chloride shift and Donnan equilibrium, either in chloride-rich (top panel) or chloride-free and high-bicarbonate (bottom panel) ASs for RBC storage. 


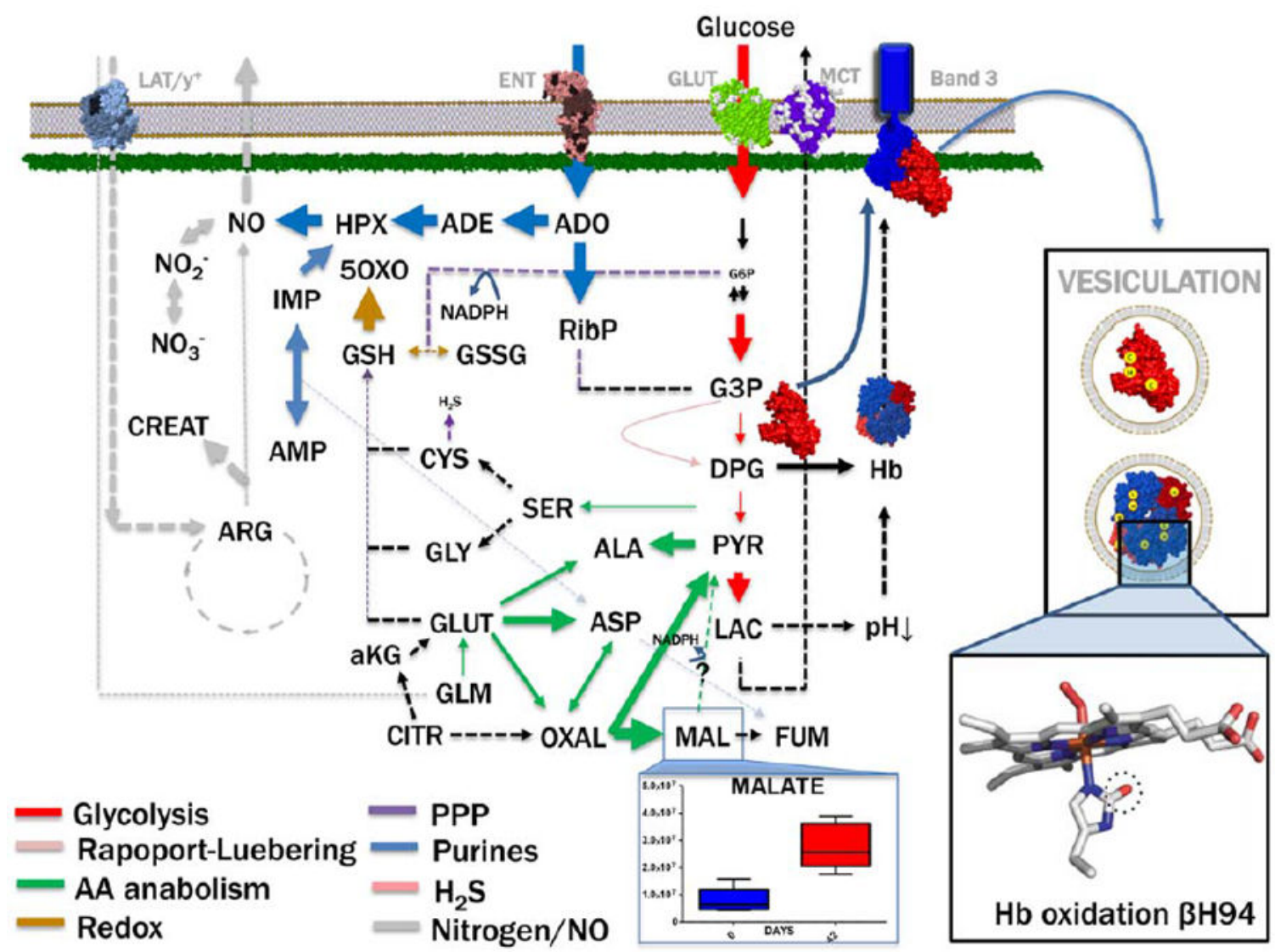

Fig. 4.

An overview of the main metabolic pathways affected by the storage lesion in RBCs during routine storage in the blood bank. Lipolysis and lipid oxidation are excluded for simplification. Of note, omics technologies, such as proteomics and interactomics, ${ }^{40,41}$ have revealed the unanticipated complexity of the RBC metabolic machinery, suggesting that cytosolic versions of Krebs cycle enzymes (e.g., malate dehydrogenase, alanine and aspartate transaminases, ATP citrate lyase, fumarase, and pyruvate carboxylase) might allow the mature RBC to metabolize tri- and dicarboxylates, as an alternative route to generate reducing coenzymes NADH and NADPH other than glycolysis and the pentose phosphate pathway. Malate levels in RBCs stored in AS-3 are adapted from D' Alessandro et al. ${ }^{68}$ Oxidative stress-dependent modulation of metabolic enzymes (G6PDH) and functional proteins involved in oxygen transport and oxygen-dependent metabolic modulation ${ }^{50}$ are adapted from Wither et al. ${ }^{105}$ and Haines et al. (under review). 

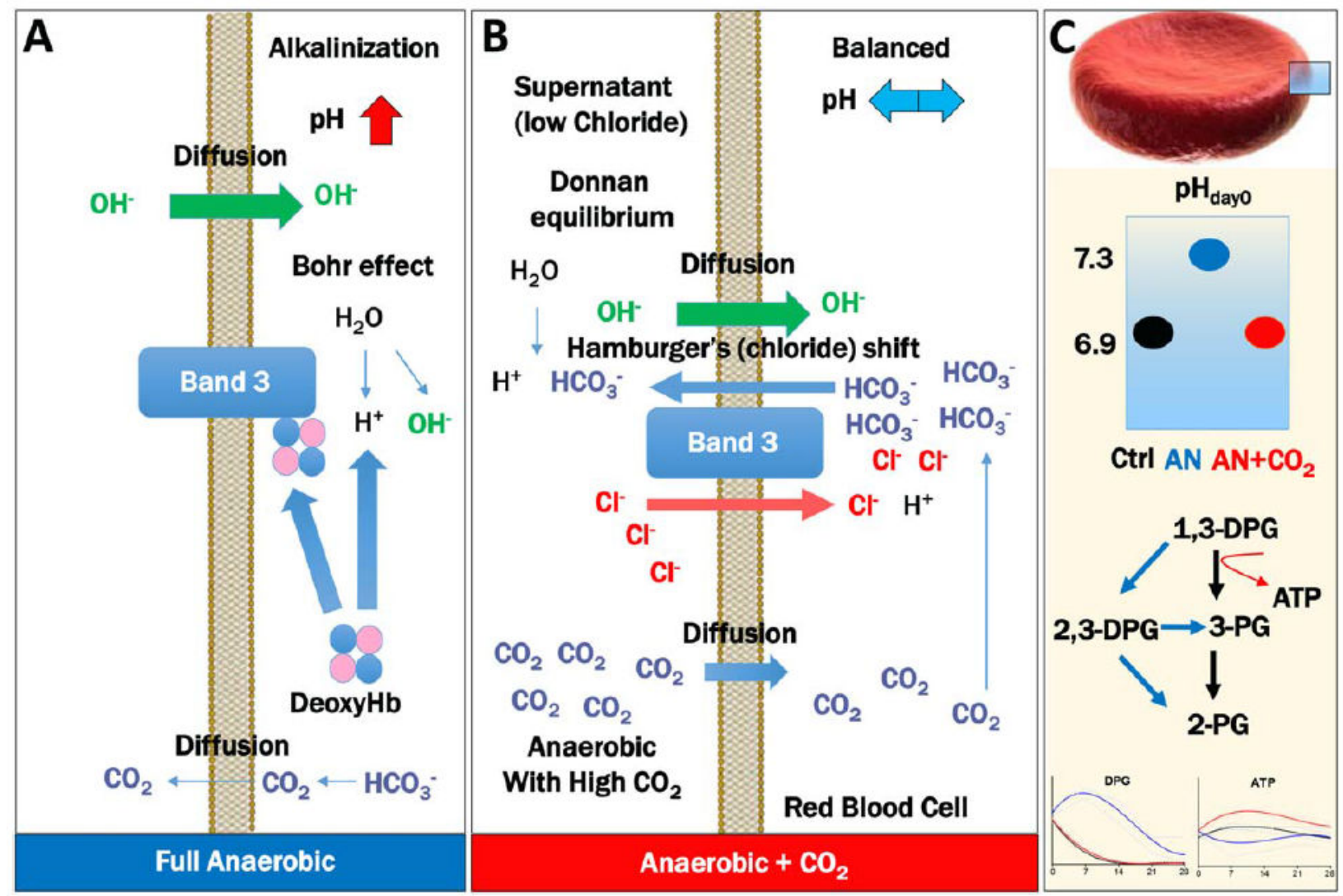

Fig. 5.

Anaerobic storage of RBCs has been shown to convey some metabolic benefits, especially in relation to energy metabolism. It can be argued that complete anaerobiosis or sustained hypoxia $\left(\mathrm{O}_{2}<10 \%\right)$ promotes intracellular alkalinization, by removing $\mathrm{CO}_{2}$ along with oxygen, promoting bicarbonate $\left(\mathrm{HCO}_{3}^{-}\right)$ion loss by backward reactions of carbonic anhydrase to produce $\mathrm{CO}_{2}$, which then diffuses through the membrane (A). To balance ion homeostasis, Donnan equilibrium promotes $\mathrm{OH}^{-}$diffusion inside the cells. Both these events, together with deoxyhemoglobin scavenging of the Bohr proton to stabilize the T state of hemoglobin, result in the intracellular alkalinization of the cytosol. To disentangle the relative contribution to hypoxia and $\mathrm{pH}$, Dumont and colleagues ${ }^{98}$ recently stored $\mathrm{RBCs}$ in presence of $5 \% \mathrm{CO}_{2}$, which promotes $\mathrm{pH}$ balance despite hypoxic conditions, through the mechanisms (B). Briefly, intracellular bicarbonate ions increase upon $\mathrm{CO}_{2}$ diffusion inside the cells and conversion to bicarbonate by carbonic anhydrases; excess bicarbonate ions are exchanged with chloride anions through the Hamburger's (chloride) shift, a Band 3 dependent anion-exchange mechanism; finally, increased intracellular levels of chloride, a stronger acid than bicarbonate, result in the acidification of the cytosolic milieu. (C) Illustrates that supplementation of $\mathrm{CO}_{2}$ under hypoxic conditions promotes initial $\mathrm{pH}$ normalization to control levels (black), resulting in higher ATP and lower DPG in comparison to hypoxic RBCs without $\mathrm{CO}_{2}$ supplementation (blue). Other than based on a 
pH effect on BPGM activity (see Fig. 2), this phenomenon is also driven by the loss of ATP generation when trioses are rerouted through the Rapoport-Luebering shunt (C). 


\section{TABLE 1}

Summary of the main metabolomics studies on transfusion medicine

\begin{tabular}{|c|c|c|c|}
\hline Authors & Year & Reference & Summary \\
\hline Messana et al. & 1999 & 34 & Quantitative determination of RBC metabolic fluxes by ${ }^{13} \mathrm{C}$ and ${ }^{1} \mathrm{H} \mathrm{MR}$ spectroscopy. \\
\hline Messana et al. & 2000 & 50 & $\begin{array}{l}\text { Storage of nonleukoreduced RBCs results in the impairment of the capacity of RBCs to } \\
\text { activate antioxidant pathways, as gleaned through elegant flux analysis. }\end{array}$ \\
\hline Yachie-Kinoshita et al. & 2010 & 97 & $\begin{array}{l}\text { An in silico metabolomics model of RBC central pathways has been used to predict and } \\
\text { experimentally test responses to hypoxia. }\end{array}$ \\
\hline Bordbar et al. & 2011 & 43 & A comprehensive in silico model of RBC metabolic maps. \\
\hline Whillier et al. & 2011 & 75 & Glutathione synthesis is negatively affected by prolonged storage of SAGM RBCs. \\
\hline Gevi et al. & 2012 & 64 & $\begin{array}{l}\text { Human RBC storage in SAGM results in the progressive accumulation of metabolic } \\
\text { lesion. }\end{array}$ \\
\hline D’Alessandro et al. & 2012 & 66 & $\begin{array}{l}\text { Integrated omics and scanning electron microscopy analysis of SAGM RBCs suggests } \\
\text { that significant biochemical and morphologic lesions accumulate after } 2 \text { weeks of } \\
\text { storage. }\end{array}$ \\
\hline Sparrow & 2012 & 22 & $\begin{array}{l}\text { A review suggesting a key role for metabolomics in the testing of currently licensed Ass } \\
\text { and in the design and testing of novel storage strategies. }\end{array}$ \\
\hline Van't Erve et al. & 2013,2014 & 76,80 & Levels of glutathione and related metabolites in stored RBCs are heritable traits. \\
\hline D’Alessandro et al. & 2013 & 94 & $\begin{array}{l}\text { Deoxygenation of RBCs promotes energy metabolism at the expenses of the pentose } \\
\text { phosphate pathway. }\end{array}$ \\
\hline Nishino et al. & 2013 & 69 & $\begin{array}{l}\text { In silico prediction and experimental validation by capillary electrophoresis and MS of } \\
\text { metabolic phenotypes of RBCs stored in PAGGGM. }\end{array}$ \\
\hline Palotta et al. & 2014 & 88 & $\begin{array}{l}\text { Supplementation of antioxidants (vitamin } \mathrm{C} \text { and } \mathrm{N} \text {-acetylcysteine) ameliorates oxidative } \\
\text { lesions at the expense of energy metabolism. }\end{array}$ \\
\hline Roback et al. & 2014 & 70 & $\begin{array}{l}\text { Extracts of RBCs stored in AS-1 were tested weekly, with high resolution in the first } 7 \text { - } \\
\text { day period. }\end{array}$ \\
\hline Van 't Erve et al. & 2014 & 79 & $\begin{array}{l}\text { Levels of metabolites involved in energy homeostasis, such as ATP, represent heritable } \\
\text { trait in stored human RBCs. }\end{array}$ \\
\hline Zimring et al. & 2014 & 39 & $\begin{array}{l}\text { An elegant study on a mouse model of transfusion showing the relevance of donor } \\
\text { genetic background on metabolic phenotypes of stored RBCs. }\end{array}$ \\
\hline Pertinhez et al. & 2014 & 63 & $\begin{array}{l}\text { NMR technologies confirm LC-MS data on a progressive accumulation of metabolic } \\
\text { lesion to SAGM RBCs. }\end{array}$ \\
\hline Paglia et al. & 2014 & 100 & $\begin{array}{l}\text { Storage of PLT concentrates results in three distinct metabolic stages, as gleaned through } \\
\text { MS and in silico analyses. }\end{array}$ \\
\hline Thomas et al. & 2014 & 44 & $\begin{array}{l}\text { A network reconstruction model of PLT metabolic pathway was used to identify } \\
\text { metabolic signatures for aspirin resistance. }\end{array}$ \\
\hline D'Alessandro et al. & 2015 & 68 & $\begin{array}{l}\text { Storage of RBCs and supernatants in AS-3. Data cover the early effects of cell } \\
\text { processing and weekly analysis until Storage Day } 42 \text {. Significant alterations of metabolic } \\
\text { profiles were observed after storage Day } 14 \text { for both cells and supernatants. }\end{array}$ \\
\hline Patel et al. & 2015 & 101 & Gamma irradiation accelerates metabolic lesion of RBCs stored in CPDA-1. \\
\hline D'Alessandro et al. & 2015 & 65 & $\begin{array}{l}\text { AS- } 5 \text { supernatants were tested during routine storage to reveal the accumulation of } \\
\text { oxidized lipid markers and catabolism byproducts. }\end{array}$ \\
\hline van 't Erve et al. & 2015 & 103 & $\begin{array}{l}\text { Hemolysis is a heritable trait in stored human RBCs, and significant correlations between } \\
\text { hemolysis and glycolytic metabolites, purines, and lysolipid can be observed. }\end{array}$ \\
\hline D’Alessandro et al. & 2015 & 67 & $\begin{array}{l}\text { Alkaline AS-7 ameliorates energy and redox metabolic lesion markers observed in RBCs } \\
\text { stored in AS-3. }\end{array}$ \\
\hline Zimring & 2015 & 8 & A critic review on the role of omics technologies in the field of transfusion medicine. \\
\hline D'Alessandro et al. & 2015 & 6 & $\begin{array}{l}\text { An updated review on the morphology and biochemical lesion to stored RBCs, as } \\
\text { gleaned through omics technologies. }\end{array}$ \\
\hline Paglia et al. & 2015 & 99 & $\begin{array}{l}\text { Metabolomics and network analyses were performed to reveal distinct metabolic } \\
\text { phenotypes in apheresis and buffy coat PLTs. }\end{array}$ \\
\hline Bordbar et al. & 2015 & 104 & An update in silico model of the RBC metabolome. \\
\hline
\end{tabular}

Transfusion. Author manuscript; available in PMC 2018 February 01. 


\begin{tabular}{|lccl|}
\hline Authors & Year & Reference & Summary \\
\hline Dumont et al. & 2015 & 98 & Metabolomics analysis reveals a key role for $\mathrm{CO}_{2}$ content in anaerobically stored RBCs. \\
\hline
\end{tabular}

